\title{
Z Research Square \\ Expert-Generated Standard Practice Elements for Evidence-Based Home Visiting Programs Using a Delphi Process
}

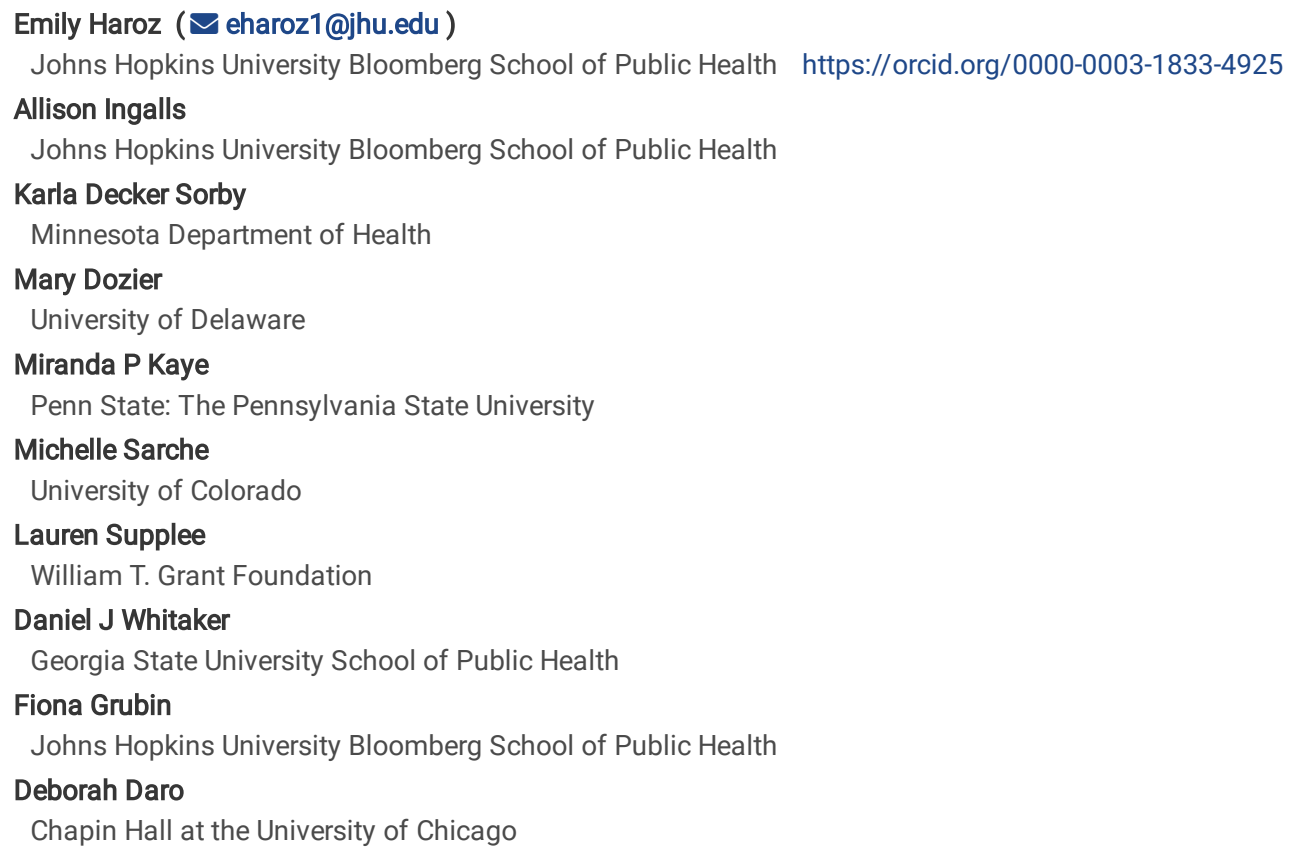




\section{Abstract}

Background. States, territories, non-profits, and tribes are eligible to obtain federal funding to implement federally-endorsed evidence-based home visiting programs. This represents a massive success in translational science, with $\$ 400$ million a year allocated to these implementation efforts. This legislation also requires that $3 \%$ of this annual funding be allocated to tribal entities implementing home visiting in their communities. However, implementing stakeholders face challenges with selecting which program is best for their desired outcomes and context. Moreover, recent reviews have indicated that when implemented in practice and delivered at scale, many evidence-based home visiting programs fail to replicate the retention rates and effects achieved during clinical trials. To inform program implementers and better identify the active ingredients in home visiting programs that drive significant impacts, we aimed to develop an expert derived consensus taxonomy on the elements used in home visiting practice that are essential to priority outcome domains.

Methods. We convened a panel of 16 experts representing researchers, model representatives, and program implementers using a Delphi approach. We first elicited standard practice elements (SPEs) using open-ended inquiry, then compared these elements to behavior change techniques (BCTs) given their general importance in the field of home visiting; and finally rated their importance to 10 outcome domains.

Results. Our process identified 48 SPEs derived from the panel, with 83 additional BCTs added based on the literature. Six SPEs, mostly related to home visitor characteristics and skills, were rated essential across all outcome domains. Fifty-three of the 83 BCTs were rated unnecessary across all outcome domains.

Conclusions. This work represents the first step in a consensus-grounded taxonomy of techniques and strategies necessary for home visiting programs and provides a framework for future hypothesis testing and replication studies.

\section{Contributions To The Literature}

- Evidence based home visiting programs are often complex and face implementation challenges including low retention and reduced effect sizes when delivered at scale.

- Given these challenges and the numerous types of evidence-based home visiting programs available, there is a need to identify the parts of home visiting programs that contribute to change, in order to inform both research and practice.

- These findings contribute to this gap by outlining an expert derived taxonomy of standard practice elements essential to effective home visiting that can be prioritized for future empirical research.

\section{Introduction}

Home visiting programs focusing on the needs of families and children began as an important strategy in the War on Poverty in the 1960s.(1) Evidence has mounted regarding the effectiveness of home visiting programs to improve maternal and child health, prevent child abuse and neglect, encourage positive parenting, and promote child development.(2-5) The American Academy of Pediatrics ${ }^{\circledR}$ endorses home visiting as a critical strategy to promote child wellbeing and build lifelong health.(1) Currently, \$400 million per year through FY2022 has been allocated for home visiting programs through the federal Maternal, Infant, and Early Childhood Home Visiting (MIECHV) and Tribal MIECHV (TMIECHV) Programs. Many states also offer additional funding for home visiting beyond MIECHV funds because they recognize the importance of home visiting to family and community health and well-being. MIECHV funding is available for states, territories, nonprofit organizations, and tribal nations to provide voluntary home visiting. While there are currently 21 evidence-based models endorsed by the Home Visiting Evidence of Effectiveness (HomVEE) federal review, MIECHV grantees may choose 1 or more of 19 models that have implementation support available.(1,6) TMIECHV grantees may adopt models that are either evidence-based or a promising approach, due to the limited amount of evidence of effectiveness of home visiting programs in tribal communities.(7) Family Spiritß is currently the only home visiting model that meets HHS criteria for evidence of effectiveness.

Home visiting models and their respective interventions are diverse in their theoretical underpinnings and vary in their specific aims, target population, type of home visitors/providers and supervisors, content, schedule of visits, and means of administration. Yet, they are similar in that most provide education, support, and referrals to community services to families living in service areas. In the most comprehensive review of home visiting models, HomVEE has reviewed the available evidence on 50 different home visiting models.(8) Programs range from broad-based models that attempt to change multiple outcomes (e.g., Nurse

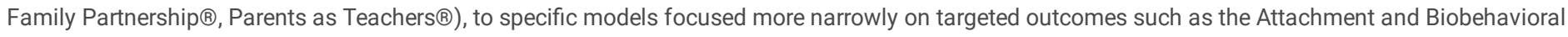
Catch-up Intervention(9) or SafeCare ${ }^{\circledR}$ to prevent child neglect and physical abuse.(10) Other home visiting models target certain types of family structures (e.g., adolescent mothers), address the needs of specific cultural or community groups (e.g., American Indian populations), focus only on a certain developmental time period (e.g., Home Instruction for Parents of Preschoolers(11)) or incorporate adjunct services for specific risks such as maternal depression.(12)

Given the number of federally-endorsed evidence-based home visiting (EBHV) programs (21 at time of publication), stakeholders across local, tribal, and state level organizations face significant challenges identifying and selecting which programs to use based solely on the evidence. For some programs, this is further complicated by the limited evidence base for the populations they serve (e.g., American Indian and Alaska Native). Those interested in implementing home visiting services face the real-world complexities of "evaluating the quality and relevance of competing programs and prioritizing certain outcomes over others in the context of limited time and resources for training and program delivery."(13)

Moreover, several key implementation challenges have been identified as EBHV programs have moved from effectiveness trials to wide scale implementation. These include challenges with client engagement and retention(4), balancing flexibility and fit during implementation with fidelity to the model that was previously tested $(14,15)$, and diminished average effect sizes as home visiting programs deliver services at scale. (6) In response to these challenges, program developers are being encouraged to unravel their approach and identify, with greater specificity, their key design elements, content, and service

Page $2 / 13$ 
delivery strategies. From the research perspective, precision home visiting (PHV) has been championed as a priority to guide this program assessment effort. (16)

The precision paradigm primarily emphasizes the importance of identifying the specific behavior change techniques within intervention models and the mechanisms of action by which those techniques promote targeted behaviors and ultimately drive outcomes.(16) While many EBHV models broadly identify target outcomes and the specific changes in participant knowledge, skills and attitudes associated in achieving outcomes, a precision lens asks program developers to apply a more specific and consistent framework in defining their efforts and monitor their implementation and impacts (Fig. 1, part A).(17) While certainly critical to explore in improving program effects, the components of a quality program often extend beyond the direct interaction between a provider and participant. Elements of a program's intervention content, implementation structure, and the required skills and personal characteristics of home visitors also contribute to an intervention's success (Fig. 1, part B).

In an effort to both simplify the decision process for implementers and potentially drive a better understanding of which intervention techniques and delivery methods should be prioritized for future studies, we sought to identify "standard practice elements" (SPEs) across a broad range of strategies that shape the structure of EBHV models. We defined SPEs as the techniques and strategies used in early childhood home visiting as part of the larger intervention. Our approach to identify SPEs was guided by a distillation and matching model, $(18,19)$ which posits that interventions are conceptualized as composites of individual strategies that can be identified and then matched to client, setting, or other factors that might be relevant for selecting which strategies are most appropriate and when.

Due to the complexities in specifying techniques across a set of models that are highly diverse in their theoretical orientation, discipline, and scope, as a first step in this process, we used a modified Delphi approach to generate a consensus-grounded taxonomy of techniques and strategies that are used across EBHV models in the United States. We pursued this aim by recruiting a panel of experts and model developers who met virtually, generated ideas using openended techniques, and refined these ideas in an interactive process. The overall goals were to: 1) synthesize the knowledge accumulated over decades of research and practice in home visiting programs to identify SPEs models considered essential to their success; and 2) create a taxonomy of early childhood EBHV SPEs, provide information to EBHV models to help them better specify efforts both within and outside the direct service delivery process, help implementers with simplifying the process of identifying and selecting interventions using the existing evidence-base for home visiting models, and ultimately inform priority hypotheses for future PHV research. We specifically focused these efforts on both non-Tribal and Tribal Home Visiting (THVs) contexts, because of the overlapping but funding streams, different processing for selecting EBHVs, and with an explicit respect for Tribes as sovereign nations within the US.

\section{Methods}

The modified Delphi process(20) was conducted over a nine-month period beginning in May 2020 and ending in January 2021 (Figure 2).

\section{Participants}

Study team members employed purposive sampling(21) to identify an expert panel including members representing early childhood home visiting researchers, allied experts from home visiting models, and leaders in THV development and implementation (21). Participants came from diverse geographic areas of the US, and represented several sectors of the home visiting field including model developers, implementers, and researchers. At the end of March 2020 , the study team emailed an invitation to participate to 22 home visiting experts. Three potential panel members were unable to participate due to other commitments. Three model developer representatives never responded to the invitation. All invited leaders in THV agreed to participate in the study. Ultimately, there were 16 members of the expert panel, each of them participating in some capacity during all three rounds of the modified Delphi process. Overall, $63 \%$ of the panel members were researchers $(n=10), 43 \%$ were model representatives $(n=7)$, and $43 \%$ were tribal stakeholders $(n=7)$.

\section{Procedures}

Our approach was guided by the Delphi method, which was developed by the RAND Corporation in the mid-20th century as a way for researchers to reliably build consensus of a group of experts $(22,23)$. Because this study took place during the COVID-19 pandemic, we modified the Delphi approach with the three rounds of questionnaires and discussion carried out via a series of Qualtrics surveys (24) and Zoom video conferences (25), coupled with email communication as necessary. Since the expert panel was only asked questions about home visiting in general and no personal information was solicited, this process was exempt from oversight by the Institutional Review Board (26).

At the start of the expert elicitation process, participants were divided into two panels: one for researchers and model developers, and one for leaders in THV. As such, two project launch meetings were conducted via Zoom video conference in May 2020 to provide expert panel members with an overview of the project prior to launching into Round 1 of the modified Delphi process.

\section{Round 1}

Both expert panels received the same survey. In this survey, free lists were used to elicit SPEs in EBHV. Free listing was selected as a feasible approach that would preserve open-ended inquiry. Participants were provided with a definition of SPEs - "the techniques and strategies used in early childhood home visiting as part of a larger intervention" - and were asked to list out all elements they considered important in early childhood home visiting. There was room to enter up to 20 individual SPEs, in addition to an open-text field for additional entries. Participants were then asked to identify which free-listed SPEs are critical to home visiting programs that serve tribal communities. Lastly, participants were asked to list any additional SPES specific to THV but not already mentioned previously. There was space for up to five individual tribal SPEs, in addition to an open-text field for additional entries. Data collection lasted for 3 weeks, concluding when the target sample size $(n=16)$ was reached. To view the full first survey, refer to Additional File 1. 
Responses to the first survey were exported and combined into one Excel file with two tabs labeled "general elements" and "tribal elements." Each tab in the Excel file had four columns: element (i.e., standard practice element label), frequency (i.e., count of respondents who free-listed the same or similar element), respondent initials (so we could follow-up if needed), and other similar descriptors (so we could see how each element was coded). Study team members read through each respondent's free-listed SPEs and decided whether each was distinct or could be combined with another element already listed in the Excel file. For example, the element "linkage to services" was listed by 12 respondents using different descriptors such as "connecting families to resources," "making a referral to appropriate community service," and "resource connection," among others. If it was unclear that listed elements were referring to the same thing, the study team kept them separate.

Two additional video conferences were held with each of the expert panels in June 2020 to further clarify and refine the list generated through the initial study. Study team members guided these group discussions in order to identify commonalities, clarify meaning, and solicit additional thoughts. In addition, during these meetings each panel independently concluded that there needed to be a broader level of categorization of SPEs to capture the multi-level hierarchy of home visiting (e.g., what are elements delivered during the visit, what are elements for home visitors training and background, etc.). As a result, via email feedback, panel members were asked to build consensus on broad category names and definitions to be used in future Qualtrics surveys.

\section{Round 2}

For Round 2, the expert panels were combined, and they remained combined through Round 3 . Thus, all email communication, subsequent surveys, and video conferences were held with the entire group of experts. In September 2020, expert panel members were asked to complete a second Qualtrics survey. In this survey, all previously elicited SPEs were presented to participants, and they were asked to group these into the broad categories defined in Round 1. Because each SPE was listed as a multi-select question type, they were able to be grouped into multiple broad categories. At the end of the survey, participants had the option to add additional SPEs that were not already included in the master list. Data collection lasted for 3 weeks, and responses were collected for $n=14$ expert panel members. The full survey is available in Additional File 2.

The second phase of Round 2 included a second video conference held with all expert panel members at the beginning of October 2020 . The study team presented the results of the second survey and asked follow-up questions to further collapse or clarify SPEs. This included re-wording of some elements and the addition of elements to better capture specific practice activities. These additions were done through consensus processes across panel members. Due to several elements that continued to need clarity, expert panel members were asked to complete a third, brief Qualtrics survey to help finalize the list of SPEs. Participants were also asked for further input (i.e., "Is this definitely a standard practice element in home visiting?") on free-listed elements that were initially provided by only one panel member in the first Qualtrics survey. Data collection lasted for a little over 1 week, concluding when the target sample size ( $\mathrm{n}=16$ ) was reached. To view the full survey, refer to Additional File 3.

\section{Data analysis for Round 2}

Responses to the first survey in Round 2 were exported, and a study team member tallied the number of responses for each SPE under each broad category. The full study team then met to make decisions about final SPE-broad category matching. A rule was created that for any SPEs that were added to a broad category by the majority of respondents (greater than $50 \%$ ), it would be considered assigned to that category. For example, the SPE "teaching goal setting skills to parents" was voted by nine expert panel members as belonging to the broad category "home visiting content." Since that is more than half of the 14 total respondents to that survey, it was coded in that category for the final results. Ties were discussed as a study team. Responses for the second survey in Round 2 were similarly exported and analyzed with SPEs only included in the round 2 list if greater than $50 \%$ of respondents endorsed their inclusion.

\section{Round 3}

To align with other efforts in the PHV field $(16,17)$, and to keep consistent with several home visiting program approaches aimed at changing parental behavior, at the beginning of this final round of the modified Delphi process, study team members engaged in an internal process to match expert-generated SPEs to the Behavior Change Technique Taxonomy.(27) The Behavior Change Technique Taxonomy was developed by researchers in the United Kingdom through a Delphi process in order to provide structure for reporting on behavior change interventions. Behavior change techniques (BCT) are strategies that help an individual change their behavior to help achieve better health. Identifying and understanding the mechanisms of BCTs are the current focus of most PHV research. Our approach to defining SPEs was intentionally broader - focusing not just on individual change, but techniques and strategies used broadly in early childhood home visiting programs to effect change. First, a full list of SPEs and BCTs was created, along with definitions and examples for each item in the list. The Behavior Change Technique Taxonomy had published definitions and examples, but the study team created definitions and examples for the panel-generated SPEs based on our panel discussion notes and from experience in the home visiting field.

The list of SPEs and BCTs was input into a Qualtrics survey using the "Pick, Group, and Rank" question type to facilitate independent coding between two internal coders from the study team. Each coder independently filled out the survey by dragging and dropping panel-generated SPEs into matching BCTs. The two coders and Principal Investigator discussed the results of the survey and came to consensus about any disagreements in the coding. Afterward, a final list of all SPEs and BCTs was created.

For the final Round 3 of Delphi surveys, panel members completed a Qualtrics survey to prioritize SPEs and BCTs to outcome domains in evidence-based home visiting (Additional File 4). Outcome domains selected for this project were adapted from the Home Visiting Evidence of Effectiveness review and the Pew Home Visiting Data for Performance Initiative $(28,29)$ with two additional tribal outcome domains that were of interest to the study team. Domains included: 1) promotion of healthy physical child development (e.g., healthy eating, breastfeeding); 2) promotion of social-emotional learning; 3 ) improving cognitive development (e.g., language development); 4) linkages and coordination of referrals for other community resources and supports; 5) reductions in 
maternal distress (e.g., depression, anxiety, stress); 6) reductions in substance use; 7) promotion of positive parenting practices; and 8) reductions in child maltreatment. Domains specific to THV included: 9) reductions in tribally-related health disparities (e.g., Type 2 Diabetes, Mental Health); and 10) promotion of connection to culture. Because the list of SPEs and BCTs was so long, each expert panel member was randomly assigned to complete the matching survey for only four outcome domains. Ratings were chosen based on methods used in a previous study by McLeod et al.(30) and included: $0=$ "Not necessary," 1 = "Useful, but not essential," and 2 = "Essential" to achieve the outcome. Expert panel members rated each SPE and BCTs according to their importance in achieving the outcome domain. Data collection lasted for 7 weeks, concluding when the target sample size ( $n=16)$ was reached. To view the full final survey, refer to Additional File 5 .

Data analysis for Round 3

Data were exported and combined in Excel for each outcome domain. For each element, frequency of ratings (e.g., Not necessary, Useful, Essential) and average ratings were tallied for each outcome domain. Average ratings were used as an indicator for strength of the relationship between the element and the outcome which were analyzed as heatmaps to help with visualization of the results.

\section{Final taxonomy}

Final taxonomies of SPEs and BCTs were developed for each outcome domain. This was done by retaining any SPE or BCT that was rated as "Essential" to that outcome domain by $50 \%$ or more of respondents.

\section{Results}

\section{Round 1}

In total, there were 58 SPEs free listed by expert panelists in the first Qualtrics survey, along with 10 unique THV SPEs, creating a total of 68 free-listed EBHV SPEs. Of these, 51 general SPEs were also thought to be critical to THV. After the Zoom video conference to discuss survey results, the list was revised to comprise a new total of 69 SPEs, including 11 THV SPEs. Group consensus was reached on n=5 broad category names, definitions, and examples (See Table 1).

\section{Round 2}

After the second Qualtrics survey, the list of SPEs included $n=62$ individual elements ( 51 general, and 11 unique to THV) categorized into $\mathrm{n}=5$ broad categories. Results from the group discussion and third Qualtrics survey lead to a reduction in total number of SPEs ( $n=45$, including 5 unique to THV). The frequencies by broad category name for the final round 2 survey can be found in Table 1 . The category with the most SPEs assigned to it was home visiting process/ delivery $(n=24)$, followed by program implementation $(n=15)$ and home visitor personal characteristics $(n=11)$. Model philosophy and home visiting content each had six SPEs assigned to them.

\section{Round 3}

After internal matching of SPEs to BCTs, the draft taxonomy grew to 38 SPEs, 10 SPEs/BCTs that overlapped, and 83 BCTs. Expert panel members used this list to rate each element by importance to achieving each outcome domain. Figure 3 presents a heatmap that displays the average rating of each element by outcome domain, with darker shade indicating higher average rating across participants. Average ratings range from 0 to 2.0 . The highest rated element across all outcome domains was "relationship building" while nine elements were rated zero across all outcome domains. All of the elements that were rated zero across all outcome domains were from the BCT.

\section{Final Taxonomy}

Using the cut off of $50 \%$ or more respondents rating the element as 'Essential' to classify the element as essentia/ to changing the specified outcomes, the number of SPEs and BCTs classified as essential by domain can be found in Table 2. Maternal distress included the most number of SPEs and BCTs with 51 elements (34 SPEs and 17 BCTs) classified as essential. No BCTs were classified as essential to increasing referrals as all 22 elements came from the expert generated SPEs.

Altogether, six SPEs were rated essential across all outcome domains while 54 elements were not rated as essential across any of the outcome domains (Table 3). Five out of the six SPEs rated as essential for all outcome domains represented key personal characteristics and skills of home visitors (Table 3). The one additional SPE not related to home visitor personal characteristics was: "Culturally attuned and responsive approach with all staff training, strategies, materials" (Table 3). Content based home visiting techniques that emerged as highly rated across $90 \%$ of outcomes included 1) Providing clients with linkages to services; and 2) Maternal risk screening and assessment (Table 3). Across all ten outcome domains of home visiting, 75 SPEs were classified as essential to achieve at least one outcome, but only fifteen elements were classified as essential across at least nine of the outcome domains (Table 3 ) .

Figure 3 shows a heatmap for SPEs and BCTs rated across all outcome domains and a sum of their ratings across all domains except for the two tribal home visiting specific outcomes. Again, many of the most highly rated SPEs and BCTs relate to home visitor personal characteristics or non-specific skills such as "Relationship building." Additional content based home visiting techniques that emerged as highly rated included: 1) Creating action plans based on child screenings; and 2) Teaching problem solving skills (Figure 3). Home visitor content mastery was also highly rated despite relatively lower content based home visiting techniques identified as essential across outcomes. This may be because some models include specific content related to a limited set of outcomes (e.g. SafeCare focuses content only on prevention of child maltreatment). All but one of the 54 elements that never achieved an essential rating by more than $50 \%$ or respondents were from the behavior change taxonomy, with the exception of "Home visitor sense of humor," which was an SPE. 


\section{Discussion}

The development of a consensus-grounded taxonomy of techniques and strategies used across EBHV programs sets the foundation for necessary next steps in the implementation and scaling EBHV programs. First, the home visiting research field has begun to explore the potential benefits of conducting PHV studies to strengthen programs and outcomes for families. A necessary part of PHV research is to identify the core techniques and strategies that may drive outcomes. Without consensus on which techniques and strategies are most promising to investigate, the PHV research may end up with a proliferation of studies with an inability to replicate findings and draw cohesive conclusions. Second, identifying the core techniques and strategies has the potential to help those identifying and selecting EBHV interventions that best meet their communities' and families' needs. For example, our findings suggest that, regardless of the home visiting model used, focusing on the qualifications and skills of home visitors is critical to maximizing outcomes. Moreover, programs can use Fig. 3 to identify key features of home visiting programs that are considered important to include in programming for the selected outcome(s).

Our results indicated that across 10 common outcome domains of home visiting, 75 SPEs were classified as essential for home visiting models to include to achieve at least one outcome. While we included ratings for BCTs, very few BCTs were identified as essential to achieving outcomes in home visiting. The highest rated BCTs overlapped with expert-generated SPEs and included: "Information sharing (by home visitor to client)" and "Teaching problem solving skills to parents." Moreover, 10 of the SPEs identified as essential across almost all outcome domains related to home visitor personal characteristics and nonspecific trained skills rather than content-based techniques or delivery methods. These results suggest that while some content-based home visiting techniques and delivery methods are essential to achieving outcomes, the process by which content is delivered and who it is delivered by may actually drive change in priority outcomes. This finding is consistent with findings in the psychotherapy field.(31) Future work is needed to identify important characteristics of home visitors, and training approaches for these home visitors in the skills that are hypothesized to drive effective programming.

From the outset of this process, the expert panel members emphasized a need to think about how SPEs fit into broader based categories of program implementation and effectiveness. The five broad based categories that were identified included: 1) Model philosophy; 2) Home visiting content; 3) Home visitor personal characteristics; 4) Home visiting process/delivery; and 5) Program implementation. These broad categories are consistent with the home visiting precision paradigm and point to a need for further studies that focus not only on the active ingredients of a particular model, but also consideration for how implementation science principles impact the context of home visiting. The context of the home visiting program plays a key role in affecting outcomes. Implementation outcomes are known in the literature to affect participant outcomes, particularly prevention of child maltreatment.(32) There is a need to understand what types and how implementation strategies can contribute to addressing the current challenges in the home visiting field.

Despite behavior change being considered a key activity in home visiting programs through home visitor support of parents to engage in healthy behavior and positive parenting,(33) few of the existing behavior change strategies overlapped with the expert-developed list of SPEs and almost none were considered essential to achieving home visiting outcomes across any outcome. This is notable, particularly in the context of the PHV field. Much of existing PHV work has been focused around a paradigm that behavior change is the ultimate goal in most home visiting programs. Therefore, the existing Behavior Change Technique Taxonomy should provide a rather exhaustive list of the elements necessary to achieve this change.(34) However, experts who participated in this Delphi process clearly did not agree that BCTs drive positive change in home visiting. Changing behavior may be more complicated than specific techniques and may rather focus on a combination of characteristics, techniques, and implementation context that ultimately translates to effective programming. While our investigation focused on ten outcomes of home visiting programs, it is possible that BCTs may be particularly relevant to certain types of outcomes such as changing unhealthy eating habits (35-37) which were not captured in our approach. Our findings also point to the need to broaden our consideration of active ingredients to test in PHV to investigate and include the SPEs identified here.

Due to the unique contexts and funding streams for THV efforts, and the need to prioritize populations who face significant health disparities, our process focused explicitly on identifying SPEs for eight standard outcomes with the addition of two outcomes that were determined to be particularly relevant for THV contexts: 1) Promoting a connection to culture; and 2) Reducing tribally relevant health disparities. The SPEs that focused specifically on the home visitor's cultural knowledge, awareness, humility, and sensitivity were considered particularly important for these outcomes. This is consistent with the broader prevention literature in tribal communities,(38) but also relevant when working on prevention efforts in any community.(39)

Bridging the research-to-practice gap by summarizing EBHV models' "standard practice elements" and, ultimately, identifying those that are common or overlapping may be particularly useful for several reasons. First, it may better inform practice because it begins to build a framework for stakeholders that would more easily enable them to personalize their programming to ensure all desired elements are available. While we did not perform a meta-analysis, our approach may help implementers identify where models overlap or are distinct from one another and use this information to select or tailor their own approaches. Second, our approach does not provide information about the impact of each SPE on outcomes, but instead provides a starting point for researchers to identify which elements might be tested further in their pursuit of identification of empirically supported active ingredients. And third, our hope is to contribute to a shared vision of improving the health and wellbeing of families and communities. Identifying common practices across EBHV models can ultimately lead to more structured tailoring of interventions to better fit the unique needs of participating families.

\section{Limitations}

There are limitations to consider when interpreting the results of this study. First, the evidence base for each SPE was not considered because the purpose was to identify a wide range of possible elements that could be considered. Second, while we attempted to link these elements to a relevant theory in the behavior change literature, other theories or conceptual frameworks may also be considered and might further strengthen this approach. Third, while we attempted to include experts representing a variety of stakeholder perspectives, our sampling is not fully representative of the home visiting field. For example, we did not include the voice of home visitors or clients, who may place value on other elements. Finally, the list of combined SPEs and BCTs and number of outcomes was large, preventing coding by all participants. Further refinement of the final taxonomy and by a wider audience may be helpful. 


\section{Conclusion}

This project represents a preliminary step in identifying SPEs that cut across EBHV programs. By starting with open-ended processes (i.e., free listing) we were able to elicit a wide range of potential SPEs based on extensive expertise in the field. This type of inquiry is especially helpful in generating hypotheses. The field of PHV is dedicated to identifying active ingredients, but knowing where to start in terms of which active ingredients to investigate and why is a critical first step in any scientific endeavor. In the short term, models can use the information included in this manuscript to ensure their programs include the essential elements. Next steps for further research might involve refinement of this initial taxonomy with a broader range of stakeholders and ultimately coding of actual program materials to identify common practice elements across models. The move towards identifying SPEs across models holds potential to overcome existing implementation challenges and ultimately strengthen impact on children's and parents' health, increase home visitor efficiency, and lower program cost while increasing economic and societal benefit.

\section{Abbreviations}

$\mathrm{BCT}=$ behavior change technique

$\mathrm{EBHV}=$ evidence-based home visiting

HomVEE=Home Visiting Evidence of Effectiveness

MIECHV=Maternal, Infant, and Early Childhood Home Visiting

$\mathrm{PHV}=$ precision home visiting

SPE=standard practice element

THV=tribal home visiting

TMIECHV=Tribal Maternal, Infant, and Early Childhood Home Visiting

US=United States

\section{Declarations}

\section{Ethics approval and consent to participate}

Not applicable

\section{Consent for publication}

Not applicable

\section{Availability of data and materials}

Available upon reasonable request

\section{Competing interests}

The authors declare that they have no competing interests.

\section{Funding}

This research was funded by the Annie E. Casey Foundation, Inc., and we thank them for their support; however, the findings and conclusions presented in this report are those of the author(s) alone, and do not necessarily reflect the opinions of the Foundation. Author E.E.H. was also supported by the National Institute of Mental Health grant number K01MH116335.

\section{Authors' contributions}

$\mathrm{EEH}$ and $\mathrm{Al}$ conceptualized this project, led data collection, and developed the first draft of the manuscript. Al coded responses. EEH analyzed the final data. DD provided significant contributions to framing the background and discussion sections of the manuscript and also provided a detailed review and edits to all sections of the manuscript. Authors KDS, MD, MK, MS, LHS, DJW, participated in the panel processes, and reviewed, revised, and refined the manuscript. Author FG coded responses and reviewed and revised the manuscript.

\section{Acknowledgements}

We continue to be immensely honored to work on behalf of all the participating families in home visiting across the country. We gratefully acknowledge expert panel members who are co-authors on this manuscript: DD, KDS, MD, MK, MS, LHS, and DJW. In addition, we appreciate all contributions made by expert panel members who do not meet the criteria for authorship but who nonetheless provided invaluable input: Dr. Allison Barlow, Johns Hopkins Bloomberg School of Public Health, Center for American Indian Health; Jill Filene, James Bell Associates; Dr. Kathryn Harding, Prevent Child Abuse America; Dr. Christa Haring Biel, 
Children's Equity Coalition; Crystal Kee, Zero to Three; Allison Kemner, Parents as Teachers; Lisa Martin, Inter-Tribal Council of Michigan, Inc.; Dr. Nancy Rumbaugh Whitesell, Colorado School of Public Health, Centers for American Indian \& Alaska Native Health; and Dr. John Walkup, Ann \& Robert H. Lurie Children's Hospital of Chicago, Department of Psychiatry and Behavioral Health, and Northwestern University.

\section{References}

1. Duffee JH, Mendelsohn AL, Kuo AA, Legano LA, Earls MF. Early Childhood Home Visiting. Pediatrics [Internet]. 2017;140(3):e20172150. Available from: http://dx.doi.org/10.1542/peds.2017-2150

2. Sweet MA, Appelbaum MI. Is home visiting an effective strategy? A meta-analytic review of home visiting programs for families with young children. Child Dev [Internet]. 2004 Sep;75(5):1435-56. Available from: http://doi.wiley.com/10.1111/j.1467-8624.2004.00750.x

3. Sama-Miller E, Akers L, Mraz-Esposito A, Avellar S, Paulsell D, Del Grosso P. Home Visiting Programs: Reviewing Evidence of Effectiveness (Brief) [Internet]. Mathematica Policy Research; Feb [cited 2021 Apr 2]. Report No.: dedb562535124bbfb29e986500ae659c. Available from: https://ideas.repec.org/p/mpr/mprres/dedb562535124bbfb29e986500ae659c.html

4. Duggan A, Portilla XA, Filene JH, Crowne SS, Hill CJ, Lee H, et al. Implementation of evidence-based early childhood home visiting: Results from the mother and infant home visiting program evaluation. OPRE Report 2018-76A [Internet]. 2018. Available from: https://eric.ed.gov/?id=ED591049

5. Tribal Maternal, Infant, and Early Childhood Home Visiting: A Report to Congress [Internet]. [cited 2021 Jun 30]. Available from: https://www.acf.hhs.gov/opre/report/tribal-maternal-infant-and-early-childhood-home-visiting-report-congress

6. Michalopoulos C. Shea Crowne S. Portilla X. A. Lee H. Filene J. H. Duggan A. Knox V. A summary of results from the MIHOPE and MIHOPE-strong start studies of evidence-based home visiting [Internet]. Washington, D.C.: Office of Planning, Research, and Evaluation, Administration for Children and Families, U.S. Department of Health and Human Services.; Available from:

https://www.acf.hhs.gov/sites/default/files/opre/mihope_summary_brief_01_16_19_508.pdf

7. Office of Child Care (OCC): About Tribal Home Visiting [Internet]. USDHHS Administration for Children \& Families. [cited 2021 Jul 1]. Available from: https://www.acf.hhs.gov/occ/about-tribal-home-visiting

8. Paulsell D, Avellar S, Sama-Miller E, Del Grosso P. Home visiting evidence of effectiveness review: Executive summary. Available at http://www.acf.hhs.gov/programs/opre/resource/home-visiting-evidence-of-effectiveness-review-executive-summary [Internet]. Mathematica Policy Research; 2011. Available from: https://econpapers.repec.org/paper/mprmprres/87df04cf10f344939c4ffce2ee418884.htm

9. Dozier M, Meade E, Bernard K. Attachment and Biobehavioral Catch-Up: An Intervention for Parents at Risk of Maltreating Their Infants and Toddlers. In: Evidence-based approaches for the treatment of maltreated children [Internet]. Springer, Dordrecht; 2014. p. 43-59. Available from:

http://link.springer.com/10.1007/978-94-007-7404-9_4

10. Gershater-Molko RM, Lutzker JR, Violence DW-. J of F, 2003 U. Project SafeCare: Improving health, safety, and parenting skills in families reported for, and at-risk for child maltreatment. Springer [Internet]. Available from: https://link.springer.com/article/10.1023/A:1026219920902

11. Lombard A. Success begins at home: Educational foundations for preschools. Boston, MA: Lexington Books, DC Heath; 1981.

12. Ammerman RT, Putnam FW, Altaye M, Stevens J, Teeters AR, Van Ginkel JB. A Clinical Trial of In-Home CBT for Depressed Mothers in Home Visitation. Behav Ther [Internet]. 2013 Sep 1;44(3):359-72. Available from: https://www.sciencedirect.com/science/article/abs/pii/S0005789413000075

13. Boustani MM, Frazier SL, Becker KD, Bechor M, Dinizulu SM, Hedemann ER, et al. Common elements of adolescent prevention programs: minimizing burden while maximizing reach. Adm Policy Ment Health [Internet]. 2015 Mar;42(2):209-19. Available from: http://dx.doi.org/10.1007/s10488-014-05419

14. O’Brien RA, Moritz P, Luckey DW, McClatchey MW, Ingoldsby EM, Olds DL. Mixed Methods Analysis of Participant Attrition in the Nurse-Family Partnership. Prev Sci [Internet]. 2012 Jun 4;13(3):219-28. Available from: http://link.springer.com/10.1007/s11121-012-0287-0

15. Shelton RC, Cooper BR, Stirman SW. The Sustainability of Evidence-Based Interventions and Practices in Public Health and Health Care. Annu Rev Public Health [Internet]. 2018 Apr;39(1):55-76. Available from: http://dx.doi.org/10.1146/annurev-publhealth-040617-014731

16. Supplee LH, Duggan A. Innovative Research Methods to Advance Precision in Home Visiting for More Efficient and Effective Programs. Child Dev Perspect [Internet]. 2019 Jul 9;13(3):173-9. Available from: http://doi.wiley.com/10.1111/cdep.12334

17. Duggan AK, Bower KM, Zagaja C, O'Neill K, Daro D, Harding K, et al. Changing the home visiting research paradigm: Models' perspectives on behavioral pathways and intervention techniques to promote good birth outcomes [Internet]. Research Square. 2021. Available from: https://www.researchsquare.com/article/rs-154026/v1

18. Chorpita BF, Daleiden EL. Mapping evidence-based treatments for children and adolescents: application of the distillation and matching model to 615 treatments from 322 randomized trials. J Consult Clin Psychol [Internet]. 2009 Jun;77(3):566-79. Available from: http://dx.doi.org/10.1037/a0014565

19. Chorpita BF, Daleiden EL, Weisz JR. Identifying and selecting the common elements of evidence based interventions: a distillation and matching model. Ment Health Serv Res [Internet]. 2005 Mar;7(1):5-20. Available from: http://dx.doi.org/10.1007/s11020-005-1962-6

20. Hasson F, Keeney S. Enhancing rigour in the Delphi technique research. Technol Forecast Soc Change [Internet]. 2011 Nov;78(9):1695-704. Available from: https://linkinghub.elsevier.com/retrieve/pii/S0040162511000801

21. Palinkas LA, Horwitz SM, Green CA, Wisdom JP, Duan N, Hoagwood K. Purposeful Sampling for Qualitative Data Collection and Analysis in Mixed Method Implementation Research. Administration and Policy in Mental Health and Mental Health Services Research [Internet]. 2015 Sep 1;42(5):533-44.

Available from: https://doi.org/10.1007/s10488-013-0528-y

22. Okoli C, Pawlowski SD. The Delphi method as a research tool: an example, design considerations and applications. Information \& Management [Internet]. 2004 Dec 1;42(1):15-29. Available from: http://www.sciencedirect.com/science/article/pii/S0378720603001794

Page $8 / 13$ 
23. Dalkey N, Helmer O. An Experimental Application of the Delphi Method to the Use of Experts. Manage Sci [Internet]. 1963;9(3):458-67. Available from: http://www.jstor.org/stable/2627117

24. Qualtrics [Internet]. Qualtrics. 2005 [cited April 2020-January 2021]. Available from: https://www.qualtrics.com

25. Zoom Video Communications Inc. Security Guide [Internet]. Zoom Video Communications Inc.; 2016 Jul. Available from: https://d24cgw3uvb9a9h.cloudfront.net/static/81625/doc/Zoom-Security-White-Paper.pdf

26. Definition of Human Subjects Research [Internet]. [cited 2021 May 15]. Available from: https://grants.nih.gov/policy/humansubjects/research.htm

27. Michie S, Richardson M, Johnston M, Abraham C, Francis J, Hardeman W, et al. The Behavior Change Technique Taxonomy (v1) of 93 Hierarchically Clustered Techniques: Building an International Consensus for the Reporting of Behavior Change Interventions. Ann Behav Med [Internet]. 2013 Aug;46(1):81-95. Available from: https://openaccess.city.ac.uk/id/eprint/3293/

28. Outcomes [Internet]. [cited 2021 Feb 11]. Available from: https://homvee.acf.hhs.gov/outcomes

29. Daro D, Investigator C-P. The Pew Home Visiting Data for Performance Initiative: Final List of Recommended Indicators and Descriptive Variables.

30. McLeod BD, Sutherland KS, Martinez RG, Conroy MA, Snyder PA, Southam-Gerow MA. Identifying Common Practice Elements to Improve Social, Emotional, and Behavioral Outcomes of Young Children in Early Childhood Classrooms. Prev Sci [Internet]. 2017 Feb;18(2):204-13. Available from: http://dx.doi.org/10.1007/s11121-016-0703-y

31. Norcross JC, Lambert MJ. Psychotherapy relationships that work III. Psychotherapy [Internet]. 2018 Dec;55(4):303-15. Available from: http://dx.doi.org/10.1037/pst0000193

32. Casillas KL, Fauchier A, Derkash BT, Garrido EF. Implementation of evidence-based home visiting programs aimed at reducing child maltreatment: A metaanalytic review. Child Abuse Negl [Internet]. 2016 Mar;53:64-80. Available from: http://dx.doi.org/10.1016/j.chiabu.2015.10.009

33. Michalopoulos C, Faucetta K, Hill CJ, Portilla XA, Burrell L, Lee H, et al. Impacts on family outcomes of evidence-based early childhood home visiting: Results from the mother and infant home visiting program evaluation. Research, and Evaluation, Administration for Children and Families, US DHHS [Google Scholar] [Internet]. 2019; Available from: https://www.mathematica.org/-/media/publications/pdfs/earlychildhood/2019/mihope_impact_report_final_508.pdf

34. Michie S, Richardson M, Johnston M, Abraham C, Francis J, Hardeman W, et al. The behavior change technique taxonomy (v1) of 93 hierarchically clustered techniques: building an international consensus for the reporting of behavior change interventions. Ann Behav Med [Internet]. 2013;46(1):81-95. Available from: https://academic.oup.com/abm/article-abstract/46/1/81/4563254

35. Haire-Joshu D, Schwarz CD, Steger-May K, Lapka C, Schechtman K, Brownson RC, et al. A Randomized Trial of Weight Change in a National Home Visiting Program. Am J Prev Med [Internet]. 2018 Mar;54(3):341-51. Available from: http://dx.doi.org/10.1016/j.amepre.2017.12.012

36. Morshed AB, Tabak RG, Schwarz CD, Haire-Joshu D. The Impact of a Healthy Weight Intervention Embedded in a Home-Visiting Program on Children's Weight and Mothers' Feeding Practices. J Nutr Educ Behav [Internet]. 2019 Feb;51(2):237-44. Available from: http://dx.doi.org/10.1016/j.jneb.2018.09.001

37. Enright G, Allman-Farinelli M, Redfern J. Effectiveness of Family-Based Behavior Change Interventions on Obesity-Related Behavior Change in Children: A Realist Synthesis. Int J Environ Res Public Health [Internet]. 2020 Jun 8;17(11). Available from: http://dx.doi.org/10.3390/ijerph17114099

38. Walters KL, Johnson-Jennings M, Stroud S, Rasmus S, Charles B, John S, et al. Growing from Our Roots: Strategies for Developing Culturally Grounded Health Promotion Interventions in American Indian, Alaska Native, and Native Hawaiian Communities. Prev Sci [Internet]. 2020 Jan 1;21(1):54-64. Available from: https://link.springer.com/article/10.1007/s11121-018-0952-z

39. Manson SM. The Role of Culture in Effective Intervention Design, Implementation, and Research: Its Universal Importance. Prev Sci [Internet]. 2020 Jan;21(Suppl 1):93-7. Available from: http://dx.doi.org/10.1007/s11121-019-01065-7

\section{Tables}

Table 1. Frequency of SPEs* by category domains 


\begin{tabular}{|c|c|c|c|}
\hline $\begin{array}{l}\text { Category } \\
\text { Domain }\end{array}$ & Consensus Definition & $\begin{array}{l}\text { Number } \\
\text { of } \\
\text { Round } \\
2 \\
\text { SPEs }^{b}\end{array}$ & Examples of SPEs \\
\hline $\begin{array}{l}\text { Model } \\
\text { philosophy }\end{array}$ & $\begin{array}{l}\text { The tenets of an evidence-based home visiting program that drive the other } \\
\text { components of home visiting, including a model's theory of change and } \\
\text { cultural lifeways. }\end{array}$ & 6 & $\begin{array}{l}\text { Model is based on a parenting framework; } \\
\text { Home visitor understands, affirms, and } \\
\text { respects cultural identity of clients (THV)* }\end{array}$ \\
\hline $\begin{array}{l}\text { Program } \\
\text { implementation }\end{array}$ & $\begin{array}{l}\text { Strategies, techniques, structures, and processes (e.g. program design) at } \\
\text { the model/organizational/site level that relate to ensuring successful } \\
\text { delivery of the EBHV, including buy-in (community, agency, home visitor), } \\
\text { staff training, supervision, fidelity, funding, and payment structures. }\end{array}$ & 15 & $\begin{array}{l}\text { Providing clients with linkage to services; } \\
\text { Program strengthening of service } \\
\text { coordination; Culturally attuned and } \\
\text { responsive approach with all staff training, } \\
\text { strategies, materials (THV) }\end{array}$ \\
\hline $\begin{array}{l}\text { Home visiting } \\
\text { content }\end{array}$ & $\begin{array}{l}\text { The content (i.e. the "what") that is conveyed by home visitors to their } \\
\text { clients during service delivery. }\end{array}$ & 6 & $\begin{array}{l}\text { Teaching relaxation/ self-regulation skills to } \\
\text { parents; Teaching goal setting skills to } \\
\text { parents }\end{array}$ \\
\hline $\begin{array}{l}\text { Home visiting } \\
\text { process/ } \\
\text { delivery }\end{array}$ & $\begin{array}{l}\text { The strategies and techniques home visitors use during service delivery } \\
\text { with their clients. }\end{array}$ & 24 & $\begin{array}{l}\text { Child assessment and screening; Active } \\
\text { listening; Role play/ coaching; Home visitor } \\
\text { shares resources in client's Native language } \\
\text { (THV) }\end{array}$ \\
\hline $\begin{array}{l}\text { Home visitor } \\
\text { personal } \\
\text { characteristics }\end{array}$ & $\begin{array}{l}\text { Home visitor characteristics that may contribute to improvement in client } \\
\text { outcomes but that aren't typically specified in a model's theoretical/ } \\
\text { conceptual framework or their content. These are aspects of the home } \\
\text { visitor that are not an explicit part of the model. }\end{array}$ & 11 & $\begin{array}{l}\text { Home visitor flexibility/ adaptability; } \\
\text { Reliable home visitor; Home visitor sense of } \\
\text { humor }\end{array}$ \\
\hline
\end{tabular}

* SPE = standard practice element; $\mathrm{THV}=$ tribal home visiting

a Categories are not listed in order of priority, and they are not listed in a hierarchy.

b Not mutually exclusive

Table 2. SPEs and behavioral change techniques classified by $50 \%$ or more respondents as essential by domain

\begin{tabular}{|c|c|c|c|c|c|}
\hline Outcome Domain & $\begin{array}{l}\text { Number of SPEs }+ \text { Behavior } \\
\text { Change Techniques }\end{array}$ & $\begin{array}{l}\text { Number of } \\
\text { unique SPEs }\end{array}$ & $\begin{array}{l}\text { Number of unique Behavior } \\
\text { Change Techniques }\end{array}$ & $\begin{array}{l}\text { Number of non- } \\
\text { essential SPEs }\end{array}$ & $\begin{array}{l}\text { Number of non-essential } \\
\text { Behavior Change Techniques }\end{array}$ \\
\hline $\begin{array}{l}\text { Child physical } \\
\text { Development }\end{array}$ & 47 & 29 & 11 & 10 & 72 \\
\hline $\begin{array}{l}\text { Child social } \\
\text { emotional } \\
\text { learning }\end{array}$ & 40 & 37 & 3 & 9 & 80 \\
\hline $\begin{array}{l}\text { Child cognitive } \\
\text { development }\end{array}$ & 35 & 27 & 8 & 19 & 75 \\
\hline $\begin{array}{l}\text { Increased } \\
\text { referrals }\end{array}$ & 22 & 22 & 0 & 24 & 83 \\
\hline Maternal distress & 51 & 34 & 17 & 12 & 66 \\
\hline $\begin{array}{l}\text { Parental } \\
\text { substance use }\end{array}$ & 30 & 20 & 10 & 26 & 73 \\
\hline $\begin{array}{l}\text { Positive } \\
\text { parenting }\end{array}$ & 37 & 29 & 8 & 17 & 75 \\
\hline $\begin{array}{l}\text { Prevention of } \\
\text { maltreatment }\end{array}$ & 45 & 35 & 10 & 11 & 73 \\
\hline $\begin{array}{l}\text { Tribal health } \\
\text { disparities }\end{array}$ & 33 & 27 & 6 & 19 & 77 \\
\hline $\begin{array}{l}\text { Connection to } \\
\text { culture }\end{array}$ & 25 & 23 & 2 & 23 & 81 \\
\hline
\end{tabular}

Table 3. Elements classified as essential across $90 \%$ or more of the outcome domains 


\begin{tabular}{|c|c|c|c|c|c|c|c|c|c|c|}
\hline Element & $\begin{array}{l}\text { Child } \\
\text { physical } \\
\text { development }\end{array}$ & $\begin{array}{l}\text { Child } \\
\text { social } \\
\text { emotional } \\
\text { learning }\end{array}$ & $\begin{array}{l}\text { Child } \\
\text { cognitive } \\
\text { development }\end{array}$ & $\begin{array}{l}\text { Increased } \\
\text { referrals }\end{array}$ & $\begin{array}{l}\text { Maternal } \\
\text { distress }\end{array}$ & $\begin{array}{l}\text { Parental } \\
\text { substance } \\
\text { use }\end{array}$ & $\begin{array}{l}\text { Positive } \\
\text { parenting }\end{array}$ & $\begin{array}{l}\text { Child } \\
\text { maltreatment }\end{array}$ & $\begin{array}{l}\text { Tribal } \\
\text { health } \\
\text { disparities }\end{array}$ & $\begin{array}{l}\text { Connec } \\
\text { to cultu }\end{array}$ \\
\hline $\begin{array}{l}\text { 1. Relationship } \\
\text { building }\end{array}$ & $\checkmark$ & $\checkmark$ & $\checkmark$ & $\checkmark$ & $\checkmark$ & $\checkmark$ & $\checkmark$ & $\checkmark$ & $\checkmark$ & $\checkmark$ \\
\hline $\begin{array}{l}2 . \\
\text { Responsiveness } \\
\text { and sensitivity }\end{array}$ & $\checkmark$ & $\checkmark$ & $\checkmark$ & $\checkmark$ & $\checkmark$ & $\checkmark$ & $\checkmark$ & $\checkmark$ & $\checkmark$ & $\checkmark$ \\
\hline $\begin{array}{l}\text { 3. Home visitor } \\
\text { demonstrates } \\
\text { cultural } \\
\text { humility }\end{array}$ & $\checkmark$ & $\checkmark$ & $\checkmark$ & $\checkmark$ & $\checkmark$ & $\checkmark$ & $\checkmark$ & $\checkmark$ & $\checkmark$ & $\checkmark$ \\
\hline $\begin{array}{l}\text { 4. Home visitor } \\
\text { adaptability } \\
\text { with respect to } \\
\text { setting and } \\
\text { participation }\end{array}$ & $\checkmark$ & $\checkmark$ & $\checkmark$ & $\checkmark$ & $\checkmark$ & $\checkmark$ & $\checkmark$ & $\checkmark$ & $\checkmark$ & $\checkmark$ \\
\hline $\begin{array}{l}\text { 5. Home visitor } \\
\text { understands, } \\
\text { affirms, and } \\
\text { respects } \\
\text { cultural identity } \\
\text { of clients }\end{array}$ & $\checkmark$ & $\checkmark$ & $\checkmark$ & $\checkmark$ & $\checkmark$ & $\checkmark$ & $\checkmark$ & $\checkmark$ & $\checkmark$ & $\checkmark$ \\
\hline $\begin{array}{l}\text { 6. Culturally } \\
\text { attuned and } \\
\text { responsive } \\
\text { approach with } \\
\text { all staff } \\
\text { training, } \\
\text { strategies, } \\
\text { materials }\end{array}$ & $\checkmark$ & $\checkmark$ & $\checkmark$ & $\checkmark$ & $\checkmark$ & $\checkmark$ & $\checkmark$ & $\checkmark$ & $\checkmark$ & $\checkmark$ \\
\hline $\begin{array}{l}\text { 7. Providing } \\
\text { clients with } \\
\text { linkage to } \\
\text { services }\end{array}$ & $\checkmark$ & $\checkmark$ & $\checkmark$ & $\checkmark$ & $\checkmark$ & $\checkmark$ & $x$ & $\checkmark$ & $\checkmark$ & $\checkmark$ \\
\hline $\begin{array}{l}\text { 8. Maternal risk } \\
\text { assessment } \\
\text { and screening }\end{array}$ & $\checkmark$ & $\checkmark$ & $\checkmark$ & $\checkmark$ & $\checkmark$ & $\checkmark$ & $\checkmark$ & $\checkmark$ & $\checkmark$ & $x$ \\
\hline $\begin{array}{l}\text { 9. Proper } \\
\text { workloads of } \\
\text { staff/ } \\
\text { supervisors }\end{array}$ & $\checkmark$ & $\checkmark$ & $\checkmark$ & $\checkmark$ & $\checkmark$ & $X$ & $\checkmark$ & $\checkmark$ & $\checkmark$ & $\checkmark$ \\
\hline $\begin{array}{l}\text { 10. Criteria for } \\
\text { staff selection } \\
\text { are appropriate } \\
\text { for population } \\
\text { served }\end{array}$ & $\checkmark$ & $\checkmark$ & $\checkmark$ & $\checkmark$ & $\checkmark$ & $x$ & $\checkmark$ & $\checkmark$ & $\checkmark$ & $\checkmark$ \\
\hline $\begin{array}{l}\text { 11. Home visitor } \\
\text { flexibility/ } \\
\text { adaptability }\end{array}$ & $\checkmark$ & $\checkmark$ & $\checkmark$ & $\checkmark$ & $\checkmark$ & $X$ & $\checkmark$ & $\checkmark$ & $\checkmark$ & $\checkmark$ \\
\hline $\begin{array}{l}\text { 12. Reliable } \\
\text { home visitor }\end{array}$ & $\checkmark$ & $\checkmark$ & $\checkmark$ & $\checkmark$ & $\checkmark$ & $x$ & $\checkmark$ & $\checkmark$ & $\checkmark$ & $\checkmark$ \\
\hline $\begin{array}{l}\text { 13. Active } \\
\text { listening }\end{array}$ & $\checkmark$ & $\checkmark$ & $x$ & $\checkmark$ & $\checkmark$ & $\checkmark$ & $\checkmark$ & $\checkmark$ & $\checkmark$ & $\checkmark$ \\
\hline $\begin{array}{l}\text { 14. Empathetic } \\
\text { communication }\end{array}$ & $\checkmark$ & $\checkmark$ & $\checkmark$ & $x$ & $\checkmark$ & $\checkmark$ & $\checkmark$ & $\checkmark$ & $\checkmark$ & $\checkmark$ \\
\hline $\begin{array}{l}\text { 15. Home visitor } \\
\text { content } \\
\text { mastery }\end{array}$ & $\checkmark$ & $\checkmark$ & $\checkmark$ & $\checkmark$ & $\checkmark$ & $x$ & $\checkmark$ & $\checkmark$ & $\checkmark$ & $\checkmark$ \\
\hline $\begin{array}{l}\text { 16. Culturally } \\
\text { informed } \\
\text { knowledge of } \\
\text { the home } \\
\text { visitor }\end{array}$ & $x$ & $\checkmark$ & $\checkmark$ & $\checkmark$ & $\checkmark$ & $\checkmark$ & $\checkmark$ & $\checkmark$ & $\checkmark$ & $\checkmark$ \\
\hline
\end{tabular}

\section{Figures}




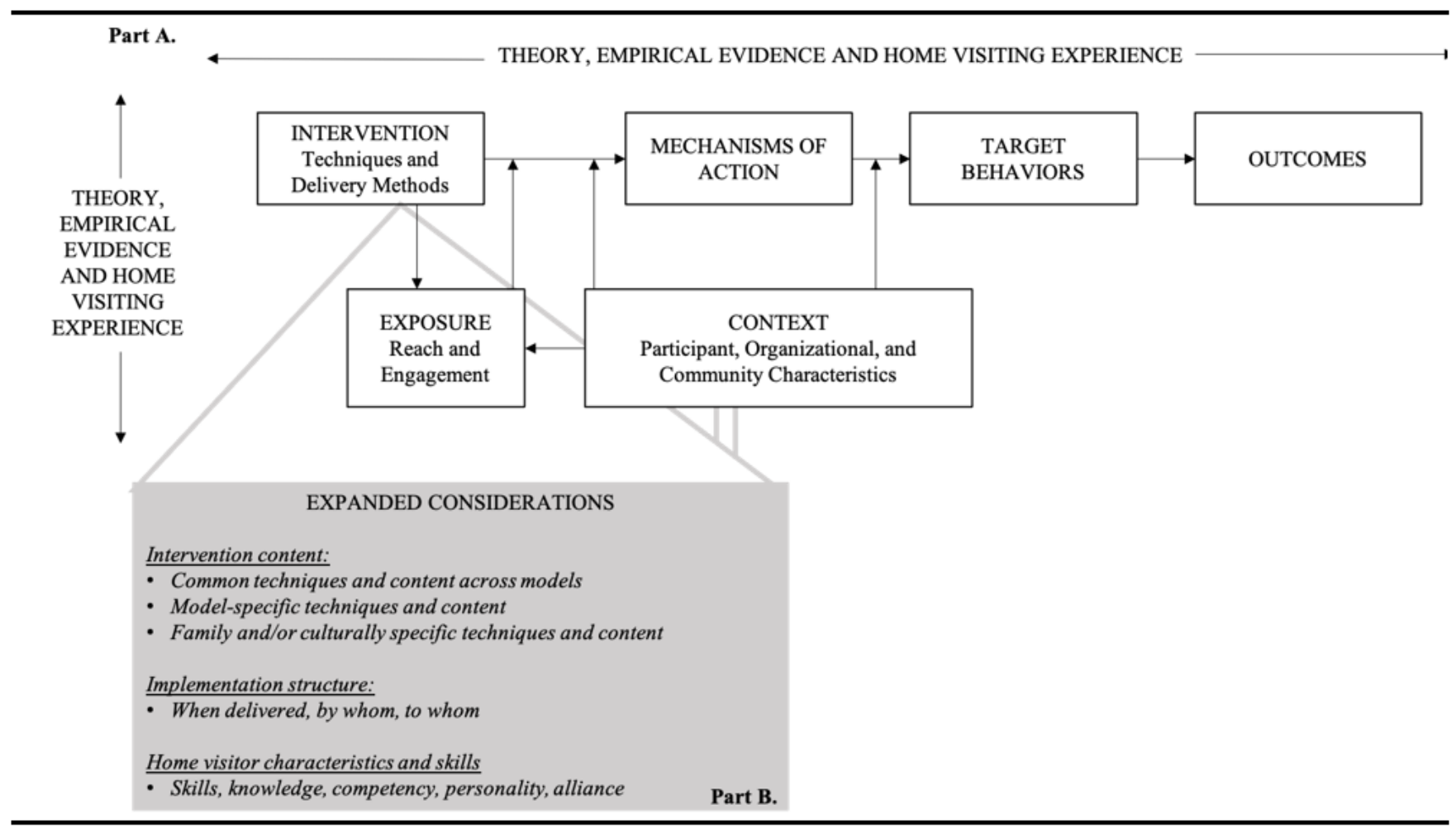

\section{Figure 1}

Expanded version of the home visiting paradigm* *Adapted from Duggan AK, Bower KM, Zagaja C, O'Neill K, Daro D, Harding K, et al. Changing the home visiting research paradigm: Models' perspectives on behavioral pathways and intervention techniques to promote good birth outcomes [Internet]. Research Square. 2021. Available from: https://www.researchsquare.com/article/rs-154026/v1 


\begin{tabular}{|c|c|c|}
\hline & Process & \multirow{3}{*}{$\begin{array}{c}\text { Taxonomy of Standard Practice Elements } \\
\text { (SPEs) }\end{array}$} \\
\hline & $\begin{array}{l}\text { Formation of expert panel and } \\
\text { overview of elicitation process } \\
\text { (March-May 2020) }\end{array}$ & \\
\hline \multirow{2}{*}{ 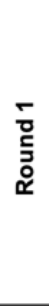 } & $\begin{array}{l}\text { Survey \#1 (May 2020) } \\
\text { Free listing of SPEs }(n=16 \\
\text { respondents) }\end{array}$ & \\
\hline & $\begin{array}{l}\frac{\text { Video Conference \#1 (June-August }}{2020 \text { ) }} \\
\text { Initial revision of panel-generated list } \\
\text { of SPEs; group consensus on broad } \\
\text { category names and definitions }\end{array}$ & $\begin{array}{l}\text { Initial list with deduplication ( } n=68 \text {, } \\
\text { includes } n=10 \text { tribal home visiting } \\
\text { (THV) SPEs) } \\
\text { Revised list ( } n=69 \text {, includes } n=11 \\
\text { THV SPEs) and } 5 \text { broad category } \\
\text { names, definitions, and examples }\end{array}$ \\
\hline \multirow{3}{*}{ 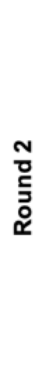 } & $\begin{array}{l}\text { Survey \#2 (September } 2020 \text { ) } \\
\text { Categorization of SPEs into broad } \\
\text { categories ( } n=14 \text { respondents) }\end{array}$ & \multirow{2}{*}{$\begin{array}{l}\text { Revised list ( } n=62 \text {, includes } 11 \\
\text { tribal home visiting SPEs) grouped } \\
\text { into broad categories }(n=5)\end{array}$} \\
\hline & $\begin{array}{l}\text { Video Conference \#2 (October 2020) } \\
\text { Revision of standard practice } \\
\text { elements }\end{array}$ & \\
\hline & $\begin{array}{l}\text { Survey \#3 (October 2020) } \\
\text { Clarification of select SPEs and } \\
\text { revision of taxonomy }(n=16)\end{array}$ & $\begin{array}{l}\text { Revised list ( } n=61 \text {, includes } 10 \\
\text { tribal home visiting SPEs) }\end{array}$ \\
\hline \multirow{3}{*}{ 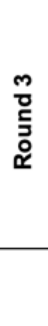 } & $\begin{array}{l}\text { Matching SPEs to Michie's Behavior } \\
\text { Change Technique (BCT) Taxonomy }\end{array}$ & $\begin{array}{l}\text { Revised list ( } n=45 \text {, includes } 5 \text { tribal } \\
\text { home visiting SPEs) }\end{array}$ \\
\hline & $\begin{array}{l}\text { Survey \#4 (December 2020-January } \\
\frac{2021}{\text { Prioritization of SPEs and BCTs to }} \\
\text { selected outcome domains }(n=16)\end{array}$ & \multirow{2}{*}{$\begin{array}{l}\text { Revised list of SPEs }(n=38) \text {, } \\
\text { SPEs/BCTs that overlapped }(n=10) \text {; } \\
\text { added unique BCTs }(n=83) \text { for a } \\
\text { total of } N=131 \text { SPEs/BCTs } \\
\text { Final taxonomy ( } N=75 \text { SPEs \& } \\
\text { BCTs) prioritized to selected EBHV } \\
\text { outcome domains \& analyzed as } \\
\text { heatmaps }\end{array}$} \\
\hline & & \\
\hline
\end{tabular}

Figure 2

Modified Delphi Process Gray boxes represent preparatory steps by the research team; white rectangular boxes outlined in black illustrate core events for collecting input and decision-making; and bolded text represents the development of a taxonomy of evidence-based home visiting standard practice elements. The members of the research are not included in the numbers of respondents to surveys.

\section{Supplementary Files}

This is a list of supplementary files associated with this preprint. Click to download.

- AdditionalFile1.Qualtricssurvey1.pdf

- AdditionalFile2.Qualtricssurvey2.pdf

- AdditionalFile3.Qualtricssurvey3.pdf

- AdditionalFile4.InternalteammatchingtoBCTs.pdf

- AdditionalFile5.Qualtricssurvey4.pdf 